\title{
Colonic Phytobezoar Caused by Popcorn Kernels Resulting in a High Grade Large Bowel Obstruction
}

\author{
Lara Mckean Baste and Avery Walker*
}

Department of Colon and Rectal Surgery, Ochsner Clinic Foundation, USA

*Corresponding author: Avery Walker, Department of Colon and Rectal Surgery, Fellow, Colon and Rectal Surgery, Ochsner Clinic Foundation, USA, Tel: 312-465-6439, E-mail: avery.s.walker.mil@mail.mil

\begin{abstract}
Phytobezoars are the result of ingestion of indigestible or poorly digestible substances. The stomach is the most commonly affected, with the small bowel being the next most common site. The colon is a rare location for a bezoar. We report the first case of pancolonic phytobezoar from popcorn kernels causing a large bowel obstruction.
\end{abstract}

\section{Keywords}

Colonic phytobezoar, Bowel obstruction, Colonic lavage

\section{Introduction}

A bezoar is a mass found trapped in the gastrointestinal system and a phytobezoar is a type of bezoar that is made of indigestible or poorly digestible substances, mainly plant materials such as fibers, skins and seeds. These phytobezoars may be discovered incidentally or after they cause symptoms of obstruction. The majority of series of cases reported are due to gastric phytobezoars, mainly after ulcer surgery including gastrectomy or truncal vagotomy; or small bowel phytobezoars causing obstruction and even perforation requiring surgical intervention. [1,2] The occurrence of colonic obstructions caused by phytobezoar is very rare with few case reports in the literature and mainly causing rectal impaction [3]. We describe a case of a pancolonic phytobezoar causing large bowel obstruction along with a literature review.

\section{Case Report}

We present a healthy 31-year-old male who presented to the emergency department with severe anal pain. The pain had begun that morning and progressed to a constant stabbing pain. He had not been able to have a bowel movement or pass any flatus for the past 3 days. He denied any fevers, trauma to the anus, or prior history of anorectal diseases. On external anal exam, there was no evidence of perianal abscess, fissure, or fistula to explain the pain. A digital rectal exam was not performed due to discomfort. A CT scan was performed (Figure 1) prior to an exam under anesthesia, which demonstrated no evidence of intrapelvic pathology to explain the patients' pain; however multiple seed like structures were seen throughout the colon. Upon examination within the operating room, a digital rectal exam demonstrated multiple popcorn kernels within the rectal vault. A Pratt Bivalve retractor revealed moderate proctitis and even more popcorn kernels (Figure 2). A colonoscope was brought into the operating room and a colonoscopy was performed just distal to the splenic flexure due the inability to clear the kernels. Given the patients stability the procedure was aborted, and the patient was transferred to the surgical floor. He was started on a bowel regimen of GoLYTELY ${ }^{\circledR}$ twice a day along with appropriate pain control. Over the course of four days the patient passed multiple bowel movements of kernels (Figure 3), his pain resolved, and an abdominal $\mathrm{x}$-ray did not reveal any kernels within his colon.

\section{Discussion}

Phytobezoars are composed of indigestible cellulose, tannin and lignin derived from ingested vegetables and fruits [4]. There are multiple reports which have described stomach and intestinal phytobezoars after ingestion of persimmons, which is the most often cause of phytobezoars in Korea [5]. These are caused by consumption of large quantities of seeds which can occur from eating the fruit or most likely from eating the seeds by themselves or

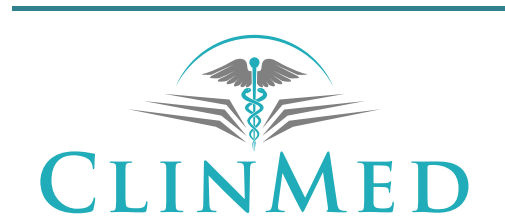

INTERNATIONAL LIBRARY
Citation: Baste LM, Walker A (2018) Colonic Phytobezoar Caused by Popcorn Kernels Resulting in a High Grade Large Bowel Obstruction. Int J Surg Res Pract 5:071. doi.org/10.23937/2378-3397/1410071 Received: April 07, 2018: Accepted: May 21, 2018; Published: May 23, 2018

Copyright: (C) 2018 Baste LM, et al. This is an open-access article distributed under the terms of the Creative Commons Attribution License, which permits unrestricted use, distribution, and reproduction in any medium, provided the original author and source are credited. 

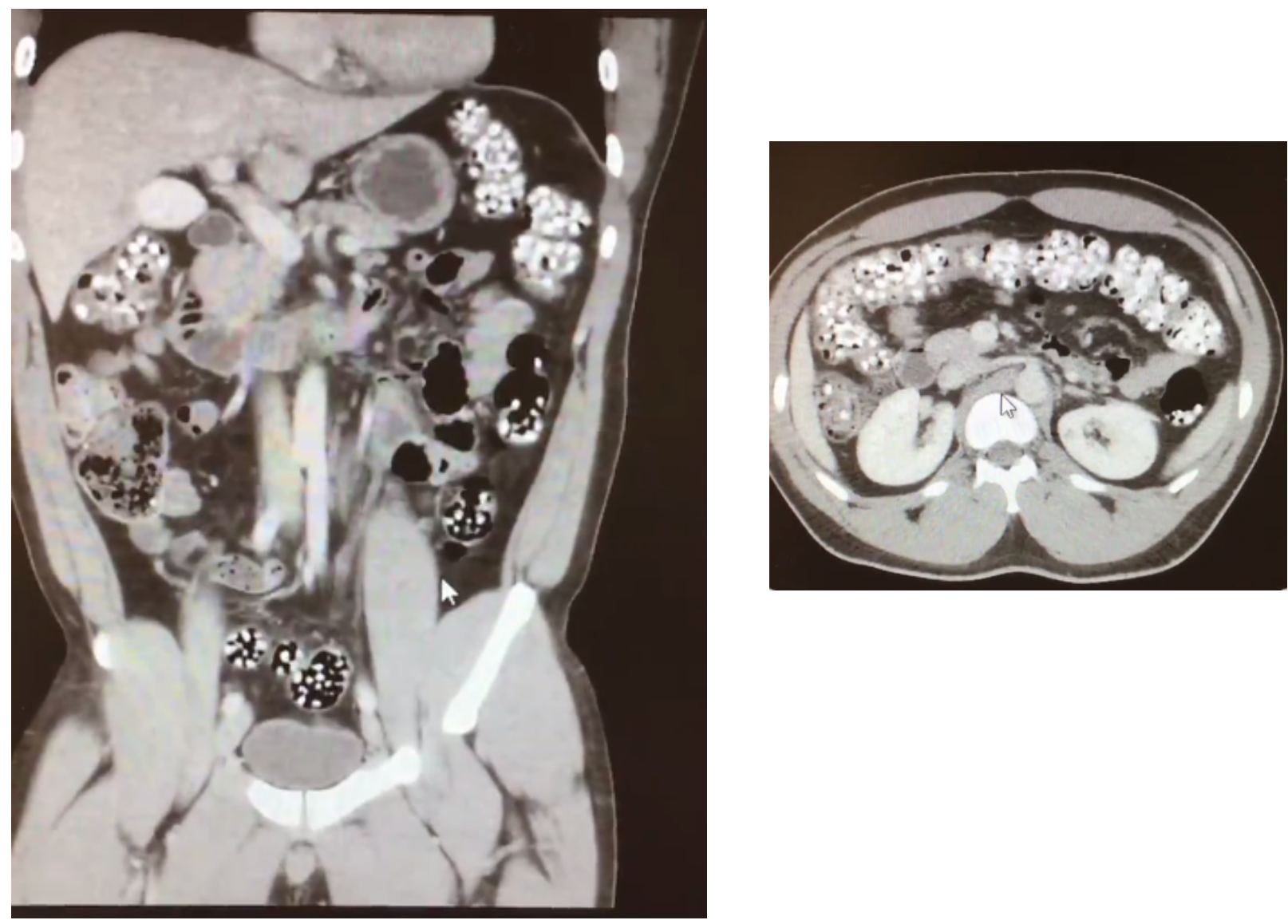

Figure 1: CT Scan demonstrating pancolonic phytobezoar.

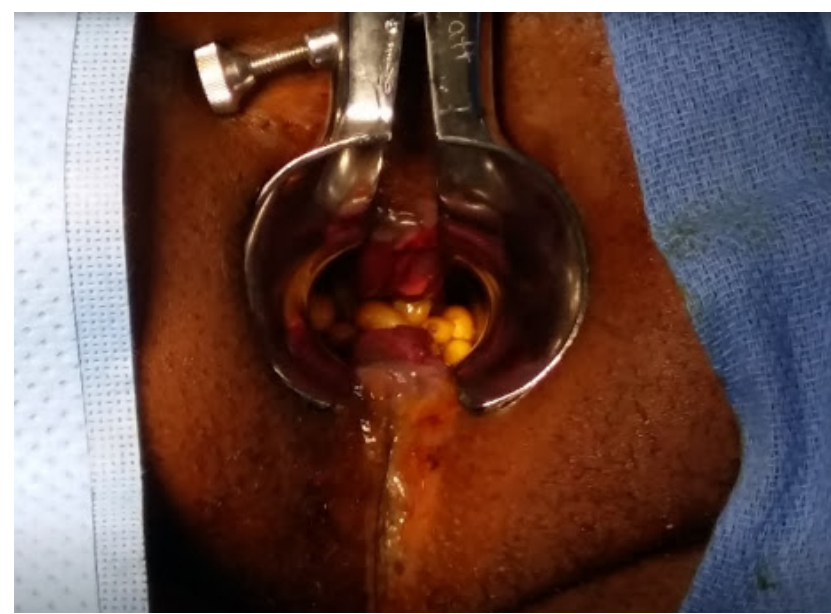

Figure 2: Pratt Bivalve retractor in place revealing popcorn kernels.

even with the outer shell [6,7]. In our case the cause of the bezoar was popcorn kernels with only a few cases reported in the literature with popcorn as the cause of a bezoar and a first causing a large bowel obstruction [8].

As causes of obstruction in the gastrointestinal tract, bezoars account for about $0.4-4 \%$, and mostly all obstructions occur in the stomach or in the ileum of the small intestine [3]. In adults, bezoar formation can be predisposed by a previous gastric procedure, incomplete mastication secondary to poor dentition, gastric stasis from gastrointestinal surgery, diabetic gastropathy, muscular atrophy, cerebral infarction, hypothyroidism, or by medications that

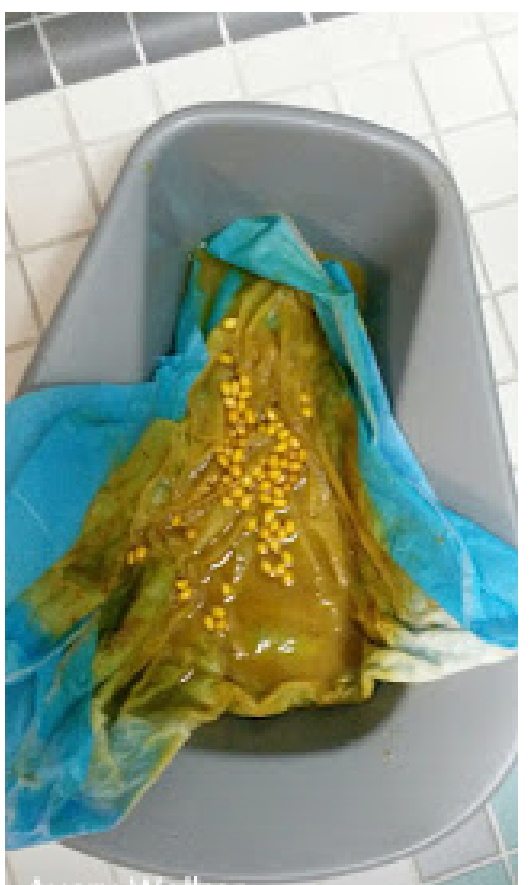

Figure 3: Multiple bowel movements with popcorn kernels.

decrease gastrointestinal motility $[3,5,9,10]$. Patients with digestive tract abnormalities such as diverticulum, adhesive bands, and strictures can also present with bezoar formation [10]. Clinical manifestations vary with the location of the bezoar. Gastric bezoars are usually associated with abdominal pain, acid reflux, and distention. When located in the small bowel or in the colon they can cause constipa- 
tion or obstruction with nausea, vomiting, abdominal pain, distension, diarrhea, loss of appetite, and weight loss $[3,5]$. On physical examination you may find the "colonic crunch sign" which is the palpation of multiple masses [11].

Complications of bezoars include obstruction, mucosal damage with ulcers caused by irritation from the bezoar. Proctitis can also occur as in our case and even perforation in some cases requiring emergent surgical intervention. Diagnosis of the entity is usually through radiology, most often by plain abdominal radiography or CT scan. $[3,5,9,10]$. In the abdominal computed tomography scan, $89 \%$ of bezoars appear as spherically-shaped masses containing air-fluid levels: Because stools appear as long solid lumps with no membranes, they are easily distinguishable from bezoars. Computed Tomography is a highly accurate method to determine the level and cause of obstruction [12]. Another diagnostic tool as well as a treatment modality is the use of endoscopy of which we used on the patient described.

The goal of treatment for colonic phytobezoars is the removal of the lesion and possible prevention of recurrence. Methods differ according to the location of the bezoars, the size, and the presence of complications $[3,5,10,12,13]$. If in the terminal region of the colon, conservative management with enemas and manual disimpaction can be used to remove the bezoar. If conservative management fails, more invasive techniques can be used such as sigmoidoscopy or colonoscopy $[5,12,13]$. Surgical management is the last resort of treatment if all other modalities have failed or when complications from the bezoar are found such as intestinal obstruction with compromised bowel, bleeding, or peritonitis $[3,5]$. Surgical management of a phytobezoar induced obstruction entails milking of the lesion to the rectum or extraction through an enterotomy [7,14-17].

This previous section describes the best approach to phytobezoars going from a more conservative treatment to most radical if needed. This description adds to the medical literature by demonstrating that an algorithmic approach can often solve the problem as opposed to jumping straight to surgery. In our case we proceeded with colonoscopy but were unsuccessful passing the splenic flexure due to the great amount of popcorn kernels, so we continued treatment with a non-surgical approach of enemas and bowel preparation which successfully cleared the bezoar as a less invasive technique to clear the bezoar is most always to the benefit of the patient.

\section{Conclusion}

Colonic phytobezoar is an uncommon cause of obstruction but should be considered in the differential when patient has had previous gastrointestinal surgeries, use of gastric immotility medications, or a report of ingesting high amount of seed like materials. Plain abdominal radiography and CT scans are helpful in the diagnosis of phytobezoars. Treatment should be based on the location and size of the mass with conservative treatment approached first. Surgery is reserved for complications or failure of conservative management.

\section{Conflicts of Interest}

No conflicts of interest.

\section{References}

1. DeBakey M, Oschner A (1938) Bezoars and concretions. Surgery 4: 934-963.

2. Chisholm EM, Chung SC, Leong HT, Li AKC (1992) Phytobezoar: an uncommon cause of small bowel obstruction. Ann R Coll Surg Engl 74: 342-344.

3. Bala M, Appelbaum L, Almogy G (2008) Unexpected cause of large bowel obstruction: colonic bezoar. Isr Med Assoc J 10: 829-830.

4. Gorgone S, Di Pietro N, Rizzo AG, Melita G, Calabro G, et al. (2003) Mechanical intestinal occlusion due to phytobezoars. G Chir 24: 239-242.

5. Yoon SS, Kim MS, Kang DY, Yun TS, Jeon JH, et al. (2001) A case of successful colonoscopic treatment of colonic obstruction caused by phytobezoar. J Korean Soc Coloproctol 27: 211-214.

6. Eitan A, Bickel A, Katz IM (2006) Fecal impaction in adults: report of 30 cases of seed bezoars in the rectum. Dis Colon Rectum 49: 1768-1771.

7. Manne JR, Rangu VM, Motapothula UM, Hall MC (2012) A crunching colon: rectal bezoar caused by pumpkin seed consumption. Clin Med Res 10: 75-77.

8. Roberge RJ, Squyres NS, MacMath TL (1988) Popcorn primary colonic phytobezoar. Ann Emerg Med 17: 77-79.

9. Escamilla C, Robles Campos R, Parrilla Paricio P, Lujan-Mompean J, Liron-Ruiz R, et al. (1994) Intestinal obstruction and bezoars. J Am Coll Surg 179: 285-288.

10. Swift RI, Wood CB, Hershman MJ (1989) Small bowel obstruction due to phytobezoars. in the intact gastrointestinal tract. J R Coll Surg Edinb 34: 267-269.

11. Şenol M, Ozdemir ZU, Şahiner IT, Ozdemir H (2013) Intestinal Obstruction due to Colonic Lithobezoar: A Case Report and a Review of the Literature. Case Rep Pediatr 2013: 854975.

12. Suri S, Gupta S, Sudhakar PJ, Venkataramu NK, Sood B, et al. (1999) Comparative evaluation of plain films, ultrasound and CT in the diagnosis of intestinal obstruction. Acta Radiol 40: 422-428.

13. Andrus CH, Ponsky JL (1988) Bezoars: classification, pathophysiology, and treatment. Am J Gastroenterol 83: 476-478.

14. Yau KK, Siu WT, Law BK, Cheung HY, Ha JP, et al. (2005) Laparoscopic approach compared with conventional open approach for bezoar-induced small-bowel obstruction. Arch Surg 140: 972-975.

15. Melchreit R, McGowan G, Hyams JS (1984) "Colonic crunch" sign in sunflower seed bezoar. N Engl J Med 310: 1748-1749.

16. Agha FP, Nostrant TT, Fiddian-Green RG (1984) Giant colonic bezoar:a medication bezoar due to psyllium seed husks. Am J Gastroenterol 79: 319-321.

17. Steinberg R, Schwarz M, Gelber E, Lerner A, Zer M (2002) A rare case of colonic obstruction by 'cherry tomato' phytobezoar: A simple technique to avoid enterotomy. J Pediatr Surg 37: 794-795. 